\title{
An Overview of Chemical Profiles, Antioxidant and Antimicrobial Activities of Commercial Vegetable Edible Oils Marketed in Japan
}

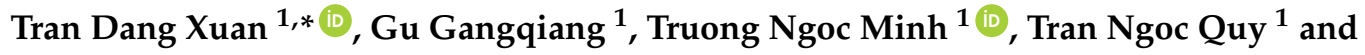 \\ Tran Dang Khanh ${ }^{2}$ \\ 1 Graduate school for International Development and Cooperation, Hiroshima University, \\ Hiroshima 739-8529, Japan; ggq353061325@gmail.com (G.G.); minhtn689@gmail.com (T.N.M.); \\ tnquy@ctu.edu.vn (T.N.Q.) \\ 2 Department of Genetic Engineering, Agricultural Genetics Institute, Pham Van Dong Street, Hanoi 122300, \\ Vietnam; khanhkonkuk@gmail.com \\ * Correspondence: tdxuan@hiroshima-u.ac.jp; Tel./Fax: +81-82-424-6927
}

Received: 30 December 2017; Accepted: 7 February 2018; Published: 10 February 2018

\begin{abstract}
This study analyzed chemical components and investigated the antioxidant and antimicrobial activities of fourteen vegetable edible oils marketed in Japan. High-performance liquid chromatography (HPLC) was used to identify and quantify principal phenolic acids and flavonoids. In the 1,1-diphenyl-2-picrylhydrazyl (DPPH) radical scavenging assay, sunflower, safflower, canola, soybean, Inca inchi, sesame, and rice bran showed markedly greater activity, whilst the percentage of lipid peroxidation inhibition (LPI\%) in sunflower, canola, cotton, grape, flax, perilla, Inca inchi, perillartine, and rice bran were significantly higher than other oils. Maximum total phenol content (TPC) was recorded in flax, followed by perillartine, rice bran, and perilla, whereas total flavonoid content (TFC) was the greatest in Inca inchi and sesame. Benzoic acid was the most common constituent, followed by vanillic acid, $p$-hydroxybenzoic acid, ferulic acid, and $p$-coumaric acid. On the other hand, luteolin was the most abundant flavonoid, followed by esculetin, myricetin, isoquercetin, and kaempferol, while fisetin was detected only in sunflower. In general, all of the edible oils showed antimicrobial activity, but the growth inhibition of Staphylococcus aureus and Escherichia coli of cotton, grape, chia, sesame, and rice bran were greater than other oils.
\end{abstract}

Keywords: edible oils; antimicrobial activity; antioxidant activity; phenolic acids; flavonoids

\section{Introduction}

Edible vegetable oils are important sources of fatty acids (mainly unsaturated), which are predominantly triglycerides (95-98\%), whist the remaining (5-2\%) consists of complex mixtures of minor compounds such as sterols, triterpenic dialcohols, diglycerides, and squalene [1-5]. Antioxidants and antibacterial activities are key agents for improving oxidative stability. Aluyor and Ori-Jesu [6] noted that the shelf life of edible oils in food uses and their applicability in industry were greatly dependent on their oxidative stability and antibacterial activity.

Like humans, foods also need to be protected from oxidation. Foods in general have antioxidant additives to avoid lipid oxidation, which results in off-flavor development [7-13]. As oxidation in foods is a chain process, a trace amount of antioxidant is required to suppress the process of oxidation [14]. Reactive oxygen species (ROS) are formed during normal cellular metabolism, but they become toxic when present in high doses [15]. Caponio et al. [16] reported that polar substances such as triglyceride oligopolymers and oxidized triglycerides found in microwaved were higher in quantity than in conventionally heated olive oil. 
In recent years, phenolic acids and flavonoids have been reported to contain multifunctional properties and beneficial effects on human health, among which polyphenols have attracted great attention [17]. Edible oils contain a number of phenolic compounds, which contribute to oxidative stability, and may serve as antioxidants to reduce the stress of oxidation on human health [18]. The DPPH (1,1-diphenyl-2-picrylhydrazyl) radical scavenging activity and $\beta$-carotene bleaching methods are two of the most commonly methods used to determine antioxidant activities [18]. Phenolic compounds have been known as potential agents for preventing and treating many oxidative stress-related diseases, such as cardiovascular disease, cancer, aging, diabetes mellitus, and neurodegenerative diseases $[19,20]$.

Edible oils extracted from plant sources are important in foods and other industries [21]. Oil extracts of sulfur-rich vegetables may have potent antimicrobial activity, and could be used in food preparation to get the synergistic effect of the oils and vegetables [22]. S. aureus and E. coli are the most common bacteria found in the environment and the human body, and are opportunistic pathogens that cause severe and life-threatening infections in immunocompromised patients [21,22]. Thus, the control of these two bacteria in the food industry is required.

Japan was ranked the eleventh-largest market of vegetable oils in 2016, with US $\$ 1.51$ billion worth of retail value sales. Between 2012 and 2016, the world vegetable oil products market grew at a compound annual growth rate (CAGR) of $8.16 \%$, while that of Japan was 5.61\% [23]. A significant portion $(41.3 \%)$ of edible oils sold in Japan in 2016 were coconut, grapeseed, groundnut, sesame, and blended oils [23]. It is estimated that by 2021, the retail values of edible oils in Japan may reach US $\$ 1.88$ billion, and the growth of consumption rate in 2017-2021 is foreseen to be 4.3\% CAGR [23]. In this study, the selective criteria of the edible oils were based on their availability in markets. Extra virgin olive oil was not selected because it was not obtainable where samples were collected.

In this study, the antioxidant activity of the fourteen vegetable edible oils marketed in Japan by the DPPH radical scavenging activity and the $\beta$-carotene bleaching method were examined. Total contents of phenolics and flavonoids, as well as individual phenolic acids and flavonoids were analyzed and quantified by HPLC. The antimicrobial activity on the growth of $S$. aureus and E. coli in laboratorial bioassays were also evaluated. This study aimed to provide information for customers in Japan to have more choices on selection of edible oils available on the markets.

\section{Materials and Methods}

\subsection{Materials and Standard Chemicals}

Fourteen edible oils (sunflower, safflower, canola, soybean, cotton, grape, flax, avocado, chia, Inca inchi, perillartine, sesame, and rice bran oil) were purchased from different supermarkets in Hiroshima Prefecture, Japan, in 2016. Details are described in Table 1. Standard chemicals for the analysis of individual phenolic acids (gallic acid, protocatechuic acid, catechol, chlorogenic acid, $p$-hydroxybenzoic acid, vanillic acid, caffeic acid, syringic acid, vanillin, ferulic acid, sinapic acid, $p$-coumaric acid, benzoic acid, ellagic acid, and cinnamic acid), and flavonoids (esculetin, isoquercetin, myricetin, fisetin, morin, quercetin, luteolin, kaempferol, isohamnetin, apigenin, rhamnetin, and galangin), extracting solvents, and buffers were of analytical grade and purchased from Wako company, Tokyo, Japan.

Table 1. Fourteen edible oils and their origins.

\begin{tabular}{ccc}
\hline Name & Part Used for Oils & Produced Companies \\
\hline Sunflower & Seeds & Monte Bussan K.K., Tokyo, Japan \\
Safflower & Seeds & J-Oil Mills Inc., Tokyo, Japan \\
Canola & Seeds & The Nisshin Oillio Group, Ltd., Tokyo, Japan \\
Soybean & Seeds & Junko Inc., Tokyo, Japan \\
Cotton & Seeds & The Nisshin Oillio Group, Ltd., Tokyo, Japan \\
\hline
\end{tabular}


Table 1. Cont.

\begin{tabular}{ccc}
\hline Name & Part Used for Oils & Produced Companies \\
\hline Grape & Seeds & The Nisshin Oillio Group, Ltd., Tokyo, Japan \\
Flax & Seeds & Nippon Flour Mills Co., Ltd., Tokyo, Japan \\
Perilla & Seeds & Ohta Oilmill Co., Ltd., Aichi, Japan \\
Avocado & Seeds & Benibana Food Co., Ltd., Tokyo, Japan \\
Chia & Seeds & K-Tac Planners Co., Ltd., Tokyo, Japan \\
Inca inchi & Seeds & Arcoiris Company, Chiba, Japan \\
Perillartine & Plants & Benibana Food Co., Ltd., Tokyo, Japan \\
Sesame & Seeds & Kadoya Sesame Mills Co., Ltd., Tokyo, Japan \\
Rice bran & Bran & Tsuno Food Industrial Co., Ltd., Wakayama, Japan \\
\hline
\end{tabular}

\subsection{Extraction of Samples}

A volume of $10 \mathrm{~mL}$ of each oil was extracted twice with $20 \mathrm{~mL}$ of methanol $(\mathrm{MeOH})$ each time. The combined extracts were evaporated to dryness in a rotary evaporator at room temperature. The precipitates were weighed, dissolved in $\mathrm{MeOH}$, and kept in the dark at $4{ }^{\circ} \mathrm{C}$ for further analysis.

\subsection{Antioxidant Properties}

\subsubsection{DPPH Radical Scavenging Activity}

The DPPH scavenging activity was evaluated according to a method described by Elzaawely et al. [24]. An aliquot of $0.5 \mathrm{~mL}$ sample extracts was mixed with $0.25 \mathrm{~mL}$ of $0.5 \mathrm{mM}$ DPPH and $0.5 \mathrm{~mL}$ of $0.1 \mathrm{M}$ acetate buffer $(\mathrm{pH}$ 5.5). The mixtures were shaken vigorously and left at room temperature in the dark for $30 \mathrm{~min}$. The reduction of the DPPH radical was determined by reading the absorbance at $517 \mathrm{~nm}$ using a spectrophotometer (HACH DR/4000U, Loveland city, CO, USA). MeOH instead of oil extract was used as a control. The percentage of DPPH radical scavenging activity (RSA) was calculated as follows: RSA $(\%)=100 \times\left(\left(\mathrm{abs}_{\text {control }}-\mathrm{abs}_{\text {sample }}\right) / \mathrm{abs}_{\text {control }}\right)$, where $\mathrm{abs}_{\text {control }}$ is the absorbance of the reaction without a sample and $\mathrm{abs}_{\text {sample }}$ is the absorbance of the reaction with samples. The $\mathrm{IC}_{50}$ (inhibitory concentration) value was determined as the inhibition of a concentration necessary to decrease the DPPH radical concentration by $50 \%$ and expressed in $\mathrm{mg} / \mathrm{mL}$. Thus, a lower $\mathrm{IC}_{50}$ value indicates higher DPPH radical scavenging activity. All measurements were performed in triplicate.

\subsubsection{Determination of Antioxidant Activity with the $\beta$-Carotene Bleaching Method}

The antioxidant activity was evaluated by the $\beta$-carotene linoleate bleaching system described by Elzaawely et al. [24]. In detail, a volume of $2 \mathrm{~mL}$ of $\beta$-carotene was dissolved in $10 \mathrm{~mL}$ of chloroform and a 1-mL aliquot of a chloroform solution that was mixed with $20 \mu \mathrm{L}$ of linoleic acid and $200 \mathrm{mg}$ Tween-40. The chloroform solution was evaporated under vacuum at room temperature. Afterwards, an aliquot of $50 \mathrm{~mL}$ of oxygenated water was added, and the emulsion was vigorously shaken until complete homogenization was achieved. The obtained emulsion was freshly prepared before each experiment. A MeOH solution of $0.12 \mathrm{~mL}$ sample was mixed with $1 \mathrm{~mL}$ of the emulsion. An equal amount of $\mathrm{MeOH}$ was used as the control. The solutions were incubated at $50{ }^{\circ} \mathrm{C}$ and recorded at $492 \mathrm{~nm}$ using a spectrophotometer (HACH DR/4000U, Loveland city, CO, USA). All extracts were measured every $30 \mathrm{~min}$ up to $180 \mathrm{~min}$. The assays were carried out in triplicate. Lipid peroxidation inhibition (LPI) was calculated using the following equation:

$$
\text { LPI }(\%)=\mathrm{A}_{1} / \mathrm{A}_{0} \times 100
$$

where $A_{0}$ is the absorbance value measured at zero time for the test sample, while $A_{1}$ is the corresponding absorbance value measured after incubation for $180 \mathrm{~min}$. Therefore, a higher LPI value shows a higher antioxidant activity. 


\subsection{Determination of Total Phenolic Content}

The total phenolic content of the extracts was determined using the Folin-Ciocalteu method described previously $[25,26]$. Briefly, $0.125 \mathrm{~mL}$ of the extracts were mixed with $0.5 \mathrm{~mL}$ of distilled water and $0.125 \mathrm{~mL}$ of Folin-Cicalteu's reagent was added. After $6 \mathrm{~min}, 1.25 \mathrm{~mL}$ of $7.5 \%$ aqueous $\mathrm{Na}_{2} \mathrm{CO}_{3}$ solution was added. The solution was then adjusted to a final aliquot of $3 \mathrm{~mL}$ with distilled water and mixed vigorously. The mixture was incubated for $90 \mathrm{~min}$ at room temperature. The absorbance at $760 \mathrm{~nm}$ was recorded using a spectrophotometer (HACH DR/4000U-USA). The calibration equation for gallic acid was: $y=0.0061 x+0.0551\left(r^{2}=0.9795\right)$, where $y$ is the absorbance and $x$ is the concentration of gallic acid in $\mathrm{mg} / \mathrm{mL}$ The total phenolic content was expressed as $\mathrm{mg}$ of gallic acid equivalent per gram (GAE/g) oil extract.

\subsection{Determination of Total Flavonoid Content (TFC)}

The total flavonoid content in the oil extracts was determined using the method described by Djeridane et al. [27]. A volume of $0.5 \mathrm{~mL}$ of the sample extract was mixed with $0.5 \mathrm{~mL}$ of the $2 \%$ aluminum chloride $\mathrm{MeOH}$ solution. After $15 \mathrm{~min}$ at room temperature, the absorption was measured at $430 \mathrm{~nm}$ using a spectrophotometer (HACH DR/4000U-USA), for which $\mathrm{MeOH}$ was used as a blank sample.

\subsection{Identification of Individual Phenolic Acids and Flavonoids by HPLC}

An aliquot of $5 \mathrm{~mL}$ of each sample extract was filtered using a $0.2 \mu \mathrm{m}$ filter (KANTO Chemical, Tokyo, Japan), then injected into an HPLC instrument (JASCO PU-2089 Plus, JASCO Corporation, Tokyo, Japan, column J-Pak Symphonia C18 110A (4.6 mm $\varnothing \times 15 \mathrm{~mm})$. The analyses of phenolic acids and flavonoids were carried out using HPLC described in Xuan et al. [28] and literature. In details, a solvent system including (A) $0.1 \%$ of acetic acid, (B) $100 \% \mathrm{MeOH}$, gradient program: $5-10 \mathrm{~min}, 5-20 \%$ (A); 10-30 $\mathrm{min}, 20-80 \%$ (A); 30-40 $\mathrm{min}, 80-100 \%$ (A), wavelength: $254 \mathrm{~nm}$, and flow rate: $1.0 \mathrm{~mL} / \mathrm{min}$ ). Each sample was measured three times, and concentrations of phenolic compounds were identified and quantified in comparison with peak areas of the standards. The individual phenolic acids and flavonoids from extracts were identified and quantified by comparing with retention times and peak areas of the standards, respectively. A calibration curve (linear regression curve) for quantification was established from different dilutions $(1,10,25,50$, and $100 \mathrm{ppm})$ of each standard phenolic acids and flavonoids. The equation $Y=\mathrm{a}+\mathrm{bX}$ obtained from the calibration curve $\left(0.9<r^{2}<0\right)$ was used to calculate the concentrations of phenolic acids and flavonoids. Of which, $Y$ is the peak area of the standard compound, $a$ and $b$ are the known values obtained from the linear regression curve, and $X$ is the concentration of the identified phenolic acid/flavonoid need to quantify.

\subsection{Antimicrobial Activity Test}

\subsubsection{Agar Preparation}

An amount of $8 \mathrm{~g}$ LB broth (Lennox) $20 \mathrm{~g}$ agar powder was dissolved in $1000 \mathrm{~mL}$ distilled water, then sterilized by an autoclave for $20 \mathrm{~min}$ at $121^{\circ} \mathrm{C}$. Then, it was cooled to $55{ }^{\circ} \mathrm{C}$ and stored at $4{ }^{\circ} \mathrm{C}$ in the dark for further experimentation.

\subsubsection{Antimicrobial Test}

The antimicrobial activity of the oil extracts was evaluated according to the method described previously [29-31]. In this experiment, the LB broth medium as described above was used to grow the bacteria for $24 \mathrm{~h}$ at $37^{\circ} \mathrm{C}$. The final populations of the bacteria were standardized to $5.6 \times 10^{6} \mathrm{CFU} / \mathrm{mL}$ (S. aureus) and $1.33 \times 10^{8} \mathrm{CFU} / \mathrm{mL}$ (E. coli). An amount of $0.1 \mathrm{~mL}$ of the bacteria suspension was placed on each plate filled with the LB agar. After that, different volumes $(0.1,0.05$, and $0.01 \mathrm{mg} / \mathrm{mL})$ 
of each oil extract were poured on sterile discs ( $6 \mathrm{~mm}$ diameter), covered by filter papers, kept at $37^{\circ} \mathrm{C}$ for $24 \mathrm{~h}$, and then the inhibition zone was measured.

\subsection{Statistical Analysis}

The data was analyzed by two-way ANOVA using the Minitab 16.0 software (Sydney, Australia) for Windows. The Tukey's test was used to indicate significant difference with a level of $p<0.05$ and expressed as mean \pm standard error (SE). The correlation coefficients among the examined factors were also calculated and expressed in linear value $\left(r^{2}\right)$ at $p<0.05$.

\section{Results}

\subsection{DPPH Radical Scavenging Activity Assay}

The radical scavenging activity of the edible oil extracts was tested using DPPH, which has the advantage of being unaffected by certain side reactions, including metal ion chelation and enzyme inhibition. The antioxidant effect is proportional to the disappearance of the purple color of DPPH in test samples.

As the lower value of $\mathrm{IC}_{50}$ indicated stronger DPPH radical scavenging activity, Table 2 showed that the value of antioxidant activity of sunflower was the maximum $(0.2 \mathrm{mg} / \mathrm{mL})$; however statistically, the DPPH scavenging activities of safflower, canola, soybean, cotton, grape, Inca inchi, sesame, and rice bran were not significantly different as compared with that of sunflower. Flax and perillartine showed intermediate antioxidant properties, while avocado and chia showed the lowest DPPH radical scavenging activity.

Table 2. 1,1-Diphenyl-2-picrylhydrazyl (DPPH) scavenging and $\beta$-carotene bleaching activities of the edible oils.

\begin{tabular}{|c|c|c|}
\hline Name & DPPH Scavenging Activity $\left(\mathrm{IC}_{50}(\mathrm{mg} / \mathrm{mL})\right.$ & $\beta$-Carotene/Linoleic Acid Inhibition (LPI\%) \\
\hline Sunflower & $0.2 \pm 0.0^{\mathrm{d}}$ & $82.4 \pm 2.3^{\mathrm{a}, \mathrm{b}, \mathrm{c}, \mathrm{d}}$ \\
\hline Safflower & $0.4 \pm 0.0^{c, d}$ & $76.6 \pm 4.9^{\mathrm{b}, \mathrm{c}, \mathrm{d}, \mathrm{e}}$ \\
\hline Canola & $0.4 \pm 0.1^{\mathrm{c}, \mathrm{d}}$ & $79.0 \pm 1.3^{\mathrm{a}, \mathrm{b}, \mathrm{c}, \mathrm{d}, \mathrm{e}}$ \\
\hline Soybean & $0.362 \pm 0.0^{\mathrm{c}, \mathrm{d}}$ & $72.5 \pm 15.7^{\mathrm{d}, \mathrm{e}}$ \\
\hline Cotton & $0.4 \pm 0.027^{c, d}$ & $91.1 \pm 1.2^{\mathrm{a}, \mathrm{b}}$ \\
\hline Grape & $0.6 \pm 0.0^{\mathrm{c}, \mathrm{d}}$ & $92.3 \pm 3.1^{\text {a }}$ \\
\hline Flax & $2.4 \pm 0.2^{b}$ & $78.5 \pm 0.0^{\mathrm{a}, \mathrm{b}, \mathrm{c}, \mathrm{d}, \mathrm{e}}$ \\
\hline Perilla & $0.8 \pm 0.0^{\mathrm{c}}$ & $78.9 \pm 3.1^{\mathrm{a}, \mathrm{b}, \mathrm{c}, \mathrm{d}, \mathrm{e}}$ \\
\hline Avocado & $6.2 \pm 0.4^{\mathrm{a}}$ & $68.8 \pm 3.0 \mathrm{e}$ \\
\hline Chia & $6.1 \pm 0.4^{\mathrm{a}}$ & $67.9 \pm 0.7^{\mathrm{e}}$ \\
\hline Inca inchi & $0.4 \pm 0.0^{\mathrm{c}, \mathrm{d}}$ & $88.1 \pm 5.5^{\mathrm{a}, \mathrm{b}, \mathrm{c}}$ \\
\hline Perillartine & $2.800 .1^{\mathrm{b}}$ & $77.0 \pm 5.2^{\mathrm{a}, \mathrm{b}, \mathrm{c}, \mathrm{d}, \mathrm{e}}$ \\
\hline Sesame & $0.5 \pm 0.0^{c, d}$ & $72.9 \pm 2.6^{\mathrm{c}, \mathrm{d}, \mathrm{e}}$ \\
\hline Rice bran & $0.5 \pm 0.0 .0^{\mathrm{c}, \mathrm{d}}$ & $85.0 \pm 1.9^{\mathrm{a}, \mathrm{b}, \mathrm{c}, \mathrm{d}}$ \\
\hline
\end{tabular}

Values represent means \pm SE (standard errors) $(n=3)$. Different letters in similar column indicate significant difference $(p<0.05)$. LPI: lipid peroxidation inhibition.

\section{2. $\beta$-Carotene Bleaching Method}

The measurement of the $\beta$-carotene bleaching method is based on the loss of the yellow color of $\beta$-carotene due to its reaction with radicals which are formed by linoleic acid oxidation in an emulsion [27]. The antioxidant activity of samples is not only dependent on temperature, but also on many other factors such as the structure, the character of the lipid system, and the binding of the fatty acids [27]. The lipid peroxidation inhibition value (LPI)\% was the greatest for grape, followed by cotton, Inca inchi, rice bran, sunflower, canola, perilla, and flax, although their values were not significantly different (Table 2). The lowest value of LPI\% was found in chia, followed by avocado. Other oils possessed intermediate values of linoleic acid inhibition. 


\subsection{Total Phenolic and Flavonoid Contents}

The total phenolic content (TPC) and total flavonoid content (TFC) of the edible oils are shown in Table 3. There was a wide variation of the TPC among examined samples, of which flax was the maximum and significantly higher than other oils, followed by perillartine, rice bran, perilla, and grape. Safflower had the lowest value of TPC, whereas that of other edible oils varied between 3.01 and $11.31 \mathrm{mg}$ GAE/g extracts (Table 3). In contrast, the TFC values were not varied as much as the TPC did, of which Inca inchi recorded the maximum, followed by sesame, avocado, flax, and perilla. Besides, perillartine, chia, rice bran, and grape showed TFCs between 0.10 and $0.12 \mathrm{mg}$ rutin equivalent $(\mathrm{RE}) / \mathrm{g}$ extract, whereas that of the other oils exhibited TFC values $<0.07 \mathrm{mg} \mathrm{RE} / \mathrm{g}$ extracts (Table 3).

Table 3. Total phenolic and flavonoid contents of 14 edible oil extracts.

\begin{tabular}{ccc}
\hline Name & TPC $(\mathbf{m g}$ GAE/g OE) & TFC $(\mathbf{m g}$ RE/g OE) \\
\hline Sunflower & $4.39 \pm 0.20^{\mathrm{h}, \mathrm{i}}$ & $0.06 \pm 0.01^{\mathrm{d}, \mathrm{e}}$ \\
Safflower & $1.76 \pm 0.29^{\mathrm{j}}$ & $0.03 \pm 0.01^{\mathrm{e}}$ \\
Canola & $3.01 \pm 0.14^{\mathrm{i}, \mathrm{j}}$ & $0.07 \pm 0.01^{\mathrm{c}, \mathrm{d}, \mathrm{e}}$ \\
Soybean & $3.23 \pm 0.08^{\mathrm{h}, \mathrm{i}, \mathrm{j}}$ & $0.03 \pm 0.01^{\mathrm{e}}$ \\
Cotton & $8.22 \pm 0.39^{\mathrm{g}}$ & $0.05 \pm 0.01^{\mathrm{d}, \mathrm{e}}$ \\
Grape & $15.56 \pm 0.24^{\mathrm{d}}$ & $0.10 \pm 0.02^{\mathrm{c}, \mathrm{d}, \mathrm{e}}$ \\
Flax & $39.16 \pm 1.03^{\mathrm{a}}$ & $0.16 \pm 0.05^{\mathrm{b}, \mathrm{c}, \mathrm{d}}$ \\
Perilla & $18.07 \pm 1.11^{\mathrm{c}}$ & $0.15 \pm 0.03^{\mathrm{b}, \mathrm{c}, \mathrm{d}}$ \\
Avocado & $11.31 \pm 0.37^{\mathrm{f}}$ & $0.19 \pm 0.02^{\mathrm{b}, \mathrm{c}}$ \\
Chia & $4.86 \pm 0.30^{\mathrm{h}}$ & $0.11 \pm 0.03^{\mathrm{c}, \mathrm{d}, \mathrm{e}}$ \\
Inca inchi & $13.29 \pm 0.05^{\mathrm{e}}$ & $0.34 \pm 0.12^{\mathrm{a}}$ \\
Perillartine & $20.38 \pm 0.17^{\mathrm{b}}$ & $0.12 \pm 0.03^{\mathrm{c}, \mathrm{d}, \mathrm{e}}$ \\
Sesame & $10.46 \pm 0.50^{\mathrm{f}}$ & $0.26 \pm 0.01^{\mathrm{a}, \mathrm{b}}$ \\
Rice bran & $19.59 \pm 1.25^{\mathrm{b}, \mathrm{c}}$ & $0.11 \pm 0.01^{\mathrm{c}, \mathrm{d}, \mathrm{e}}$
\end{tabular}

Values represent means \pm SE (standard errors) $(n=3)$. Different letters in a column indicate significant difference $(p<0.05)$. GAE: gallic acid equivalent; OE: oil extract; RE: rutin equivalent; TPC: total phenolic content; TFC: total flavonoid content.

Comparing among the examined edible oils, flax, perillartine, Inca inchi, sesame, rice bran, perilla, grape, and avocado had higher levels of TPC and TFC than those of other oils, although the values did not proportionally parallel between TPC and TFC (Table 3).

\subsection{Identification and Quantification of Individual Phenolic and Flavonoid Compounds}

Eight phenolic acids were identified, including chlorogenic acid, $p$-hydroxybenzoic acid, vanillic acid, ferulic acid, sinapic acid, p-coumaric acid, benzoic acid, and ellagic acid (Figure 1). Benzoic acid and vanillic acid were the most abundant. In quantity, benzoic acid recorded the highest (0.071-0.607 $\mathrm{mg} / \mathrm{mL}$ extracts), whilst the other phenolic acids were in much lower quantities (0.004-0.079 $\mathrm{mg} / \mathrm{mL}$ extracts) (Table 4$)$.

Figure 2 shows the HPLC profile of the 12 flavonoid standards, including esculetin, isoquercetin, myricetin, fisetin, quercetin n-hydrate, quercetin, luteolin, kaempferol, isohamnetin, apigenin, rhamnetin, and galangin. Of them, 7 compounds were identified, consisting of esculetin, isoquercetin, myricetin, fisetin, luteolin, kaempferol, and rhamnetin (Table 5). In details, luteolin was the most abundant. Myricetin and esculetin were found in 7 edible oils, isoquercetin and kaempferol were observed in 5 edible oils, while rhamnetin was detected in 2 edible oils (Table 5). 


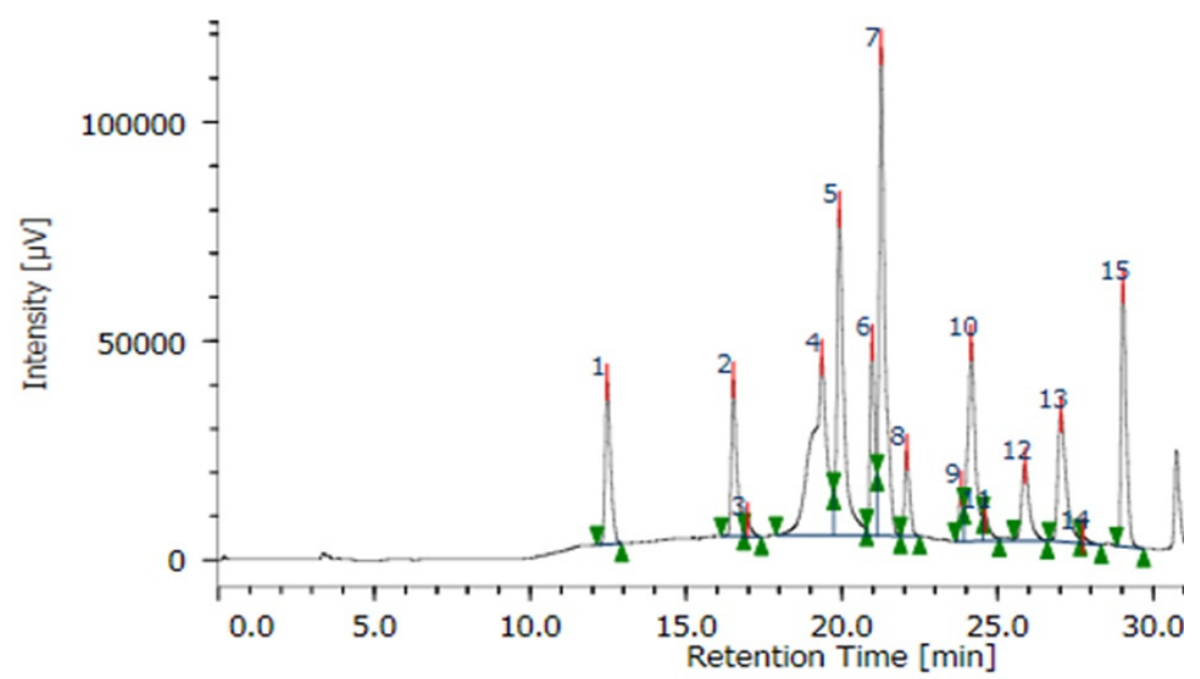

Figure 1. HPLC chromatogram of phenolic acid standards. Peaks 1: gallic acid; 2: protocatechuic acid; 3: catechol; 4: chlorogenic acid; 5: $p$-hydroxybenzoic acid; 6: vanillic acid; 7: caffeic acid; 8: syringic acid; 9: vanillin; 10: ferulic acid; 11: sinapic acid; 12: $p$-coumaric acid; 13: benzoic acid; 14: ellagic acid; 15: cinnamic acid.

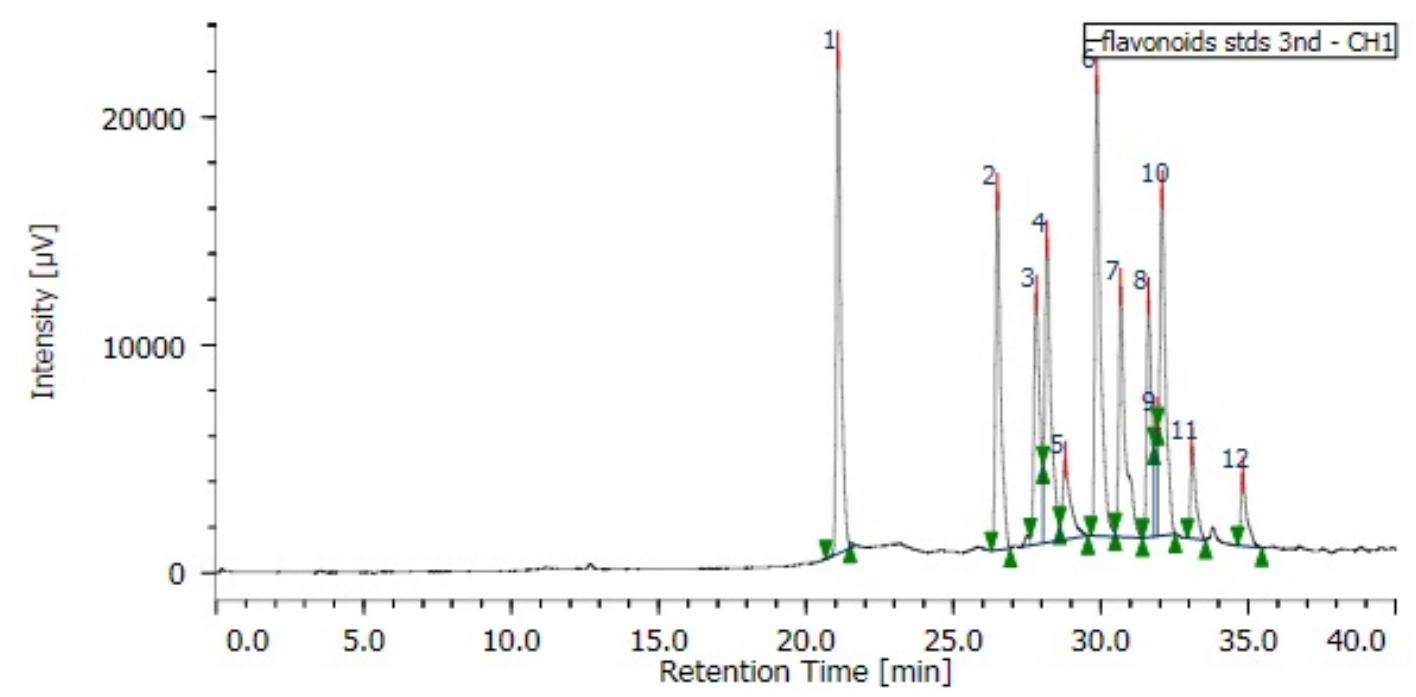

Figure 2. HPLC chromatogram of the flavonoid standards. Peaks 1: esculetin; 2: isoquercetin; 3 : myricetin; 4: fisetin; 5: quercetin n-hydrate; 6: quercetin; 7: luteolin; 8: kaempferol; 9: isohamnetin; 10: apigenin; 11: rhamnetin; 12: galangin. 
Table 4. Quantification of phenolic acids $(\mathrm{mg} / \mathrm{mL})$ detected in the 14 edible oils.

\begin{tabular}{|c|c|c|c|c|c|c|c|c|c|}
\hline \multirow{2}{*}{ Samples } & \multicolumn{9}{|c|}{ Compounds } \\
\hline & ChA & $p$-HA & VA & $\mathrm{FeA}$ & SiA & $p$-CA & BA & EA & Tota \\
\hline Su-0 & - & - & - & - & - & $0.042 \pm 0.027^{a}$ & $0.380 \pm 0.085^{a, b, c}$ & - & 0.422 \\
\hline Sa-0 & - & - & - & - & - & $0.005 \pm 0.001^{b}$ & $0.226 \pm 0.044^{b, c}$ & - & 0.231 \\
\hline $\mathrm{Ca}-0$ & - & - & - & - & - & - & $0.213 \pm 0.050^{b, c}$ & - & 0.213 \\
\hline SO-B & - & $0.007 \pm 0.003^{\mathrm{a}}$ & - & $0.004 \pm 0.001^{\mathrm{b}}$ & - & $0.005 \pm 0.001^{b}$ & - & $0.009 \pm 0.002^{b}$ & 0.025 \\
\hline Co-S & $0.040 \pm 0.013^{a}$ & - & - & - & $0.061 \pm 0.072^{\mathrm{a}}$ & $0.005 \pm 0.001^{b}$ & $0.403 \pm 0.303^{a, b, c}$ & - & $0.50 \varsigma$ \\
\hline Gr-S & - & - & $0.038 \pm 0.055^{\mathrm{a}}$ & - & - & - & $0.071 \pm 0.018^{c}$ & - & $0.10 \mathrm{~s}$ \\
\hline Fl-S & $0.079 \pm 0.023^{a}$ & - & $0.019 \pm 0.001^{\mathrm{a}}$ & - & - & - & $0.423 \pm 0.083^{\mathrm{a}, \mathrm{b}}$ & $0.019 \pm 0.001^{\mathrm{a}}$ & 0.540 \\
\hline Pe-S & $0.062 \pm 0.027^{a}$ & - & $0.043 \pm 0.029^{a}$ & $0.012 \pm 0.004^{\mathrm{a}}$ & $0.008 \pm 0.002^{a}$ & - & - & - & 0.139 \\
\hline $\mathrm{Av}-0$ & - & $0.017 \pm 0.001^{\mathrm{a}}$ & $0.031 \pm 0.003^{a}$ & - & - & - & $0.607 \pm 0.201^{a}$ & $0.007 \pm 0.001^{b}$ & 0.662 \\
\hline Ch-S & - & $0.007 \pm 0.007^{\mathrm{a}}$ & $0.023 \pm 0.004^{a}$ & - & - & - & $0.351 \pm 0.037^{a, b, c}$ & - & 0.381 \\
\hline IN-0 & - & - & $0.026 \pm 0.001^{\mathrm{a}}$ & - & - & - & $0.317 \pm 0.016^{\mathrm{a}, \mathrm{b}, \mathrm{c}}$ & - & 0.343 \\
\hline Pe-A & - & $0.006 \pm 0.004^{a}$ & $0.027 \pm 0.001^{\mathrm{a}}$ & - & - & - & $0.264 \pm 0.013^{b, c}$ & - & 0.297 \\
\hline Se-0 & - & - & & $0.008 \pm 0.002^{a, b}$ & - & - & $0.152 \pm 0.031^{b, c}$ & - & 0.160 \\
\hline \multirow[t]{2}{*}{ Ri-0 } & - & - & & $0.009 \pm 0.004^{\mathrm{a}, \mathrm{b}}$ & - & - & $0.147 \pm 0.040^{b, c}$ & - & 0.156 \\
\hline & ns & ns & ns & & ns & ns & & & \\
\hline
\end{tabular}

Values represent means \pm SE (standard errors) $(n=3)$. Different letters in similar column indicate significant difference $(p<0.05)$. ChA: chlorogenic acid; $p$-HA: $p$-hydroxybenzoic acid; VA: vanillic acid; FeA: ferulic acid; SiA: sinapic acid; $p$-CA: $p$-coumaric acid; BA: benzoic acid; EA: ellagic acid. Su-0: sunflower oil; Sa-0: safflower oil; Ca-0: canola oil; S0-B: soybean oil; Co-S: cotton seed oil; Gr-S: grape seed oil; Fl-S: flax seed oil; Pe-S: perilla seed oil; Av-0: avocado oil; Ch-S: chia seed oil; IN-0: Inca inchi oil; Pe-A: perillartine oil; Se-0: sesame oil: Ri-0: rice bran oil; -: not detected; ns: not significant. 
Table 5. Quantification of major flavonoid compounds $(\mathrm{mg} / \mathrm{mL})$ detected in the 14 edible oils.

\begin{tabular}{|c|c|c|c|c|c|c|c|c|}
\hline \multirow{2}{*}{ Samples } & \multicolumn{7}{|c|}{ Compounds } & \multirow{2}{*}{ Total } \\
\hline & Es & Is & My & $\mathbf{F i}$ & $\mathbf{L u}$ & Ka & Rh & \\
\hline Su-0 & $3.553 \pm 0.426^{\mathrm{a}}$ & $2.257 \pm 0.803^{a}$ & - & $2.900 \pm 0.100^{a}$ & $0.862 \pm 0.760^{b, c}$ & $0.731 \pm 0.271^{a}$ & - & 10.303 \\
\hline Sa-0 & - & $0.280 \pm 0.033^{b}$ & - & - & - & - & - & 0.28 \\
\hline $\mathrm{Ca}-0$ & $0.761 \pm 0.047^{c}$ & $0.227 \pm 0.033^{b}$ & - & - & - & - & - & 0.988 \\
\hline SO-B & - & - & $6.133 \pm 4.007^{\mathrm{a}, \mathrm{b}}$ & - & $0.941 \pm 0.599^{b, c}$ & - & - & 7.074 \\
\hline Co-S & - & - & $5.979 \pm 2.925^{\mathrm{a}, \mathrm{b}}$ & - & $0.728 \pm 0.420^{b, c}$ & - & - & 6.707 \\
\hline Gr-S & $1.975 \pm 0.074^{\mathrm{b}}$ & - & $4.092 \pm 0.144^{\mathrm{b}}$ & - & $0.409 \pm 0.022^{c}$ & - & $3.613 \pm 0.180^{a}$ & 10.089 \\
\hline Fl-S & $0.826 \pm 0.104^{c}$ & - & - & - & - & $0.239 \pm 0.016^{c}$ & $2.127 \pm 0.015^{b}$ & 3.192 \\
\hline Pe-S & - & - & $9.947 \pm 1.236^{\mathrm{a}}$ & - & $2.595 \pm 0.199^{a}$ & - & - & 12.542 \\
\hline$A v-0$ & - & - & $4.517 \pm 1.357^{\mathrm{a}, \mathrm{b}}$ & - & $1.607 \pm 0.151 \mathrm{a}^{\mathrm{b}, \mathrm{c}}$ & - & - & 6.124 \\
\hline Ch-S & - & - & $3.986 \pm 0.386^{b}$ & - & $1.718 \pm 0.347^{\mathrm{a}, \mathrm{b}}$ & - & - & 5.704 \\
\hline IN-0 & - & - & $4.600 \pm 0.702^{a, b}$ & - & $1.570 \pm 0.532^{a, b, c}$ & - & - & 6.170 \\
\hline Pe-A & $1.974 \pm 0.508^{b}$ & $1.096 \pm 0.429^{b}$ & - & - & - & $0.452 \pm 0.112^{a, b, c}$ & - & 3.522 \\
\hline Se-0 & $0.950 \pm 0.161^{c}$ & $0.255 \pm 0.101^{\mathrm{b}}$ & - & - & - & $0.325 \pm 0.078^{b, c}$ & - & 1.530 \\
\hline \multirow[t]{2}{*}{ Ri-0 } & $0.853 \pm 0.171^{c}$ & - & - & - & - & $0.677 \pm 0.0114^{\mathrm{a}, \mathrm{b}}$ & - & 1.530 \\
\hline & & & & ns & & & & \\
\hline
\end{tabular}

Values represent means \pm SE (standard errors) $(n=3)$. Different letters in similar column indicate significant difference $(p<0.05)$. Es: esculetin; Is: isoquercetin; My: myricetin; Fi: fisetin; Lu: luteolin; Ka: kaempferol; Rh: rhamnetin. Su-0: sunflower oil; Sa-0: safflower oil; Ca-0: canola oil; S0-B: soybean oil; Co-S: cotton seed oil; Gr-S: grape seed oil; Fl-S: flax seed oil; Pe-S: perilla seed oil; Av-0: avocado oil; Ch-S: chia seed oil; IN-0: Inca inchi oil; Pe-A: perillartine oil; Se-0: sesame oil: Ri-0: rice bran oil; ns: not significant; -: not detected. 
These flavonoids were quantified by HPLC (Figure 2), and are shown in Table 5. It was found that the identified flavonoids presented in much greater quantity than that of phenolic acids. In detail, myricetin possessed the maximum $(3.986-9.947 \mathrm{mg} / \mathrm{mL})$, followed by rhamnetin $(2.127-3.613 \mathrm{mg} / \mathrm{mL})$, whereas kaempferol was the lowest $(0.239-0.677 \mathrm{mg} / \mathrm{mL})$. The remaining isoquercetin, esculetin, and luteolin obtained $0.255-3.553 \mathrm{mg} / \mathrm{mL}$ (Table 5). Comparing the total amount of flavonoids, perilla showed the highest quantity $(12.542 \mathrm{mg} / \mathrm{mL})$, followed by grape and sunflower (10.089 and $10.303 \mathrm{mg} / \mathrm{mL}$, respectively). Safflower had the least $(0.28 \mathrm{mg} / \mathrm{mL})$, followed by canola $(0.988 \mathrm{mg} / \mathrm{mL})$, whereas both sesame and rice bran had a similar amount $(1.53 \mathrm{mg} / \mathrm{mL})$. Other edible oils had 3.192-6.707 mg/mL (Table 5).

\subsection{Antimicrobial Activity}

The antimicrobial activity of the examined edible oils is shown in Table 6. It is observed that all oils showed inhibition against growth of the two bacteria, and the inhibitory levels were proportional to the applied doses. In the $S$. aureus trial, at concentrations of $0.01-0.05 \mathrm{mg} / \mathrm{mL}$, although the suppressive magnitudes were all higher than the negative control, no significant difference was observed. At the maximum dose of $0.10 \mathrm{mg} / \mathrm{mL}$, cotton, grape, chia, sesame, and rice bran showed significantly higher levels of inhibition than the negative control. However, sunflower and Inca inchi exerted the least suppression, which was significantly lower than other oils and the positive control.

Table 6. Antimicrobial activity of the 14 edible oils.

\begin{tabular}{|c|c|c|c|c|c|c|}
\hline \multirow{2}{*}{ Sample } & \multicolumn{3}{|c|}{ S. aureus } & \multicolumn{3}{|c|}{ E. coli } \\
\hline & $0.10 \mathrm{mg} / \mathrm{mL}$ & $0.05 \mathrm{mg} / \mathrm{mL}$ & $0.01 \mathrm{mg} / \mathrm{mL}$ & $0.10 \mathrm{mg} / \mathrm{mL}$ & $0.05 \mathrm{mg} / \mathrm{mL}$ & $0.01 \mathrm{mg} / \mathrm{mL}$ \\
\hline Su-0 & $8.667 \pm 2.517^{b, c}$ & $7.000 \pm 1.732^{b}$ & $6.333 \pm 0.577^{b}$ & $10.333 \pm 1.528^{\mathrm{c}, \mathrm{d}, \mathrm{e}}$ & $8.333 \pm 2.309 \mathrm{~b}, \mathrm{c}$ & $6.667 \pm 0.577^{b}$ \\
\hline $\mathrm{Sa}-0$ & $14.000 \pm 5.000^{a, b, c}$ & $10.667 \pm 5.033^{b}$ & $9.333 \pm 3.512^{b}$ & $13.000 \pm 3.000^{b, c, d}$ & $9.667 \pm 2.082^{b, c}$ & $8.667 \pm 2.082^{b}$ \\
\hline $\mathrm{Ca}-0$ & $12.667 \pm 2.517 \mathrm{a}, \mathrm{b}, \mathrm{c}$ & $8.667 \pm 1.155^{b}$ & $6.667 \pm 0.577^{b}$ & $13.667 \pm 0.577^{b, c, d}$ & $9.667 \pm 0.577^{b, c}$ & $7.000 \pm 0.001^{b}$ \\
\hline SO-B & $13.000 \pm 1.000^{a, b, c}$ & $12.333 \pm 1.155^{b}$ & $7.333 \pm 0.577^{b}$ & $11.333 \pm 2.082^{c, d}$ & $11.667 \pm 2.309^{b}$ & $7.000 \pm 0.001^{b}$ \\
\hline Co-S & $17.667 \pm 1.155^{\mathrm{a}, \mathrm{b}}$ & $12.000 \pm 1.000^{\mathrm{b}}$ & $7.333 \pm 1.155^{\mathrm{b}}$ & $13.667 \pm 1.528^{b, c, d}$ & $12.000 \pm 1.000^{\mathrm{b}}$ & $8.000 \pm 1.000^{b}$ \\
\hline Gr-S & $16.667 \pm 6.807 \mathrm{a}, \mathrm{b}$ & $12.000 \pm 4.583^{\mathrm{b}}$ & $7.000 \pm 1.000^{\mathrm{b}}$ & $14.667 \pm 3.786^{b, c}$ & $10.000 \pm 2.000^{b, c}$ & $9.667 \pm 2.082^{b}$ \\
\hline Fl-S & $15.333 \pm 1.155^{a, b, c}$ & $9.667 \pm 2.082^{b}$ & $7.667 \pm 0.577^{\mathrm{b}}$ & $12.667 \pm 1.155^{\mathrm{b}, \mathrm{c}, \mathrm{d}}$ & $11.000 \pm 1.000^{\mathrm{b}}$ & $8.000 \pm 1.000^{b}$ \\
\hline Pe-S & $11.000 \pm 1.000^{a, b, c}$ & $7.667 \pm 1.528^{b}$ & $7.667 \pm 0.577^{b}$ & $11.667 \pm 1.528^{\mathrm{c}, \mathrm{d}}$ & $9.667 \pm 1.528^{b, c}$ & $8.667 \pm 2.517^{b}$ \\
\hline $\mathrm{Av}-0$ & $14.667 \pm 4.041^{\mathrm{a}, \mathrm{b}, \mathrm{c}}$ & $9.000 \pm 1.732^{b}$ & $6.667 \pm 0.577^{\mathrm{b}}$ & $17.000 \pm 1.000^{\mathrm{b}}$ & $10.667 \pm 0.577^{b, c}$ & $7.667 \pm 1.528^{b}$ \\
\hline Ch-S & $16.000 \pm 1.732^{a, b}$ & $13.000 \pm 3.606^{\mathrm{a}, \mathrm{b}}$ & $9.333 \pm 2.517^{b}$ & $11.000 \pm 1.000^{\mathrm{c}, \mathrm{d}, \mathrm{e}}$ & $8.667 \pm 0.577^{b, c}$ & $6.667 \pm 1.155^{b}$ \\
\hline IN-0 & $10.333 \pm 0.577 \mathrm{~b}, \mathrm{c}$ & $8.667 \pm 2.082^{b}$ & $6.333 \pm 0.577^{b}$ & $12.333 \pm 1.528^{b, c, d}$ & $10.667 \pm 0.577^{b, c}$ & $8.667 \pm 1.528^{b}$ \\
\hline Pe-A & $12.333 \pm 0.577^{\mathrm{a}, \mathrm{b}, \mathrm{c}}$ & $8.667 \pm 1.528^{b}$ & $7.000 \pm 1.000^{\mathrm{b}}$ & $9.333 \pm 1.528^{\mathrm{d}, \mathrm{e}}$ & $8.000 \pm 2.000^{b, c}$ & $7.000 \pm 1.732^{b}$ \\
\hline Se-0 & $16.000 \pm 6.557 \mathrm{a}, \mathrm{b}$ & $9.667 \pm 3.055^{b}$ & $8.000 \pm 2.646^{b}$ & $12.667 \pm 0.577^{b, c, d}$ & $11.000 \pm 0.000^{\mathrm{b}}$ & $8.667 \pm 2.309^{b}$ \\
\hline $\mathrm{Ri}-0$ & $20.333 \pm 2.082^{a}$ & $11.667 \pm 0.577^{\mathrm{b}}$ & $8.667 \pm 1.155^{b}$ & $15.333 \pm 1.155^{b, c}$ & $9.667 \pm 3.512^{b, c}$ & $7.333 \pm 1.528^{b}$ \\
\hline P-C & $20.000 \pm 1.000^{\mathrm{a}}$ & $20.000 \pm 1.000^{\mathrm{a}}$ & $20.000 \pm 1.000^{\mathrm{a}}$ & $23.000 \pm 1.000^{\mathrm{a}}$ & $23.000 \pm 1.000^{\mathrm{a}}$ & $23.000 \pm 1.000^{\mathrm{a}}$ \\
\hline $\mathrm{N}-\mathrm{C}$ & $6.000 \pm 0.001^{c}$ & $6.000 \pm 0.001^{b}$ & $6.000 \pm 0.001^{\mathrm{b}}$ & $6.000 \pm 0.0011^{\mathrm{e}}$ & $6.000 \pm 0.001^{c}$ & $6.000 \pm 0.001^{b}$ \\
\hline
\end{tabular}

In E. coli, at the lowest dose of $0.01 \mathrm{mg} / \mathrm{mL}$, no marked difference as compared with the negative control was observed (Table 6). At a higher dose of $0.05 \mathrm{mg} / \mathrm{mL}$, four oils-including soybean, cotton, flax, and sesame-exhibited remarkably higher inhibition than other oils and the negative control. At the greatest concentration of $0.10 \mathrm{mg} / \mathrm{mL}$, although the oils displayed significantly lower antimicrobial activity than the positive control, they were all remarkably greater than the negative control, except sunflower, cotton, and perilla (Table 6). In general, cotton, grape, chia, sesame, and rice bran exhibited the stronger inhibition of the growth of S. aureus and E. coli than the other oils.

\subsection{Correlation Coefficients among Analyzed Factors}

Results in Table 7 showed the correlation coefficients among total phenolic and flavonoid contents, antioxidant activity (DPPH radical scavenging activity and $\beta$-carotene bleaching assay), and total amounts of individual phenolic acids and flavonoids. It was observed that the highest correlation 
coefficient was found between the DPPH radical scavenging and $\beta$-carotene bleaching activities $\left(\mathrm{r}^{2}=0.401\right)$, followed by TPC and IPA (total amount of individual phenolic acids) $\left(\mathrm{r}^{2}=0.3235\right)$, and DPPH radical scavenging activity and IPA $\left(\mathrm{r}^{2}=0.3322\right)$. The IF (total amount of individual flavonoids) showed a greater correlation coefficient of antimicrobial activity $\left(r^{2}=0.0709-0.1496\right)$ than that of the IPA $\left(r^{2}=0.0002-0.0003\right)$ (Table 7). Total phenolic and flavonoid contents and antioxidant capacity did not show strong correlation coefficient against the antimicrobial activity of the edible oils. In general, no marked differences were observed among analyzed factors (Table 7).

Table 7. Correlation coefficients among examined factors in the 14 edible oils.

\begin{tabular}{ccccccccc}
\hline Factors & TPC & TFC & DPPH & $\beta$-Carotene & IPA & IF & S. aureus & E. coli \\
\hline TPC & & 0.1232 & 0.0118 & 0.0313 & 0.3235 & 0.0001 & 0.0431 & 0.0182 \\
TFC & & & 0.0224 & 0.0001 & 0.0314 & 0.0006 & 0.0159 & 0.0029 \\
DPPH & & & & 0.401 & 0.3322 & 0.0001 & 0.0221 & 0.0007 \\
$\beta$-Carotene & & & & & 0.0113 & 0.0647 & 0.0108 & 0.0445 \\
IPA & & & & & & 0.0001 & 0.0002 & 0.0003 \\
IF & & & & & & & 0.1496 & 0.0709 \\
\hline
\end{tabular}

Mean in column is expressed by a linear value $\left(r^{2}\right)$ at $p<0.05$. Abbreviations: TPC: total phenol content; TFC: total flavonoid content; DPPH: DPPH radical scavenging activity; $\beta$-carotene: $\beta$-carotene bleaching activity; IPA: total amount of individual phenolic acids; IF: total amount of individual flavonoids; S. aureus and E. coli: antimicrobial activity on S. aureus and E. coli.

\section{Discussion}

The results showed that the highest amount of total phenolics was in the flax seed oil extract $(39.16 \mathrm{mg} / \mathrm{g}$ ) and was significantly higher than all of other edible oils. Anwar and Przybylski [31] determined a lower content of total phenolics of $27 \mathrm{mg} / \mathrm{g}$ in flax seeds. The reason for the different results might be due to a difference in the varieties of flax seeds, extraction solvent, temperature, and equipment [32]. Even if the total phenolic content of flaxseed oil extract was remarkably greater than other edible oils, the $\mathrm{IC}_{50}$ of flax seed oil of the DPPH scavenging activity showed a low level at $2.396 \mathrm{mg} / \mathrm{mL}$, and the $\beta$-carotene bleaching value were significantly higher than the other oils (Table 2), indicating that total phenolics in flax seed oil was not proportional to its antioxidant activity. The antioxidant activity of plant extracts may relate to the presence of some individual phenolic compounds [33]. Inca inchi oil extract showed the maximum amount of total flavonoids $(0.34 \mathrm{mg} / \mathrm{g})$; however, the $\mathrm{IC}_{50}$ of the DPPH radical scavenging activity of this oil was $0.430 \pm 0.007 \mathrm{mg} / \mathrm{mL}-$ lower than sunflower, safflower, canola, soybean, and cotton (Table 2). The lowest values of TFC were in safflower and soybean ( $0.03 \mathrm{mg}$ RE/g oil extract) (Table 3$)$.

Sunflower oil extract gave the best results in the DPPH radical scavenging test, and similar capacity in the $\beta$-carotene bleaching assay as compared with other oils, except avocado and chia (Table 2). Among dietary plant sources, sunflower seeds are characterized by high antioxidant activity [33]. This oil is shown to have low total phenolic and total flavonoid contents, but the flavonoid compound fisetin was found only in sunflower oil extract. Further, esculetin, isoquercetin, and kaempferol were also identified in sunflower oil extracts and the total amount of the identified individual flavonoids (IF) was higher than other oils, except grape and perilla (Table 5). In addition, $p$-coumaric acid was found in much higher quantity in sunflower than other oils. As a result, fisetin, esculetin, isoquercetin, kaempferol, and $p$-coumaric acid might play an important role in the antioxidant activity of sunflower seed oil. Karamac et al. [33] reported that sunflower seed is an important butyraceous source grown in many countries, particularly in many European countries, to provide rich antioxidants.

Bail et al. [34] reported that the TPC of grape seed levels was at $70 \pm 1.76 \mu \mathrm{g} / \mathrm{g}$, and Doshi [35] revealed that the TPC of two grape varieties Navarang and Merlot were 65.8 and $41.7 \mathrm{mg} / \mathrm{mL}$, respectively, which was higher than the TPC of grape seed oil examined in this study (15.56 \pm $0.24 \mathrm{mg} / \mathrm{g}$ ). The TPC of grape seed was $20.02 \mathrm{mg} / \mathrm{g}$, and suggested that it might be affected by varieties and extracting protocols [36]. The $\beta$-carotene bleaching method is based on the loss of yellow 
color of $\beta$-carotene because the free radical produced from linoleic acid is able to strongly destroy unsaturated $\beta$-carotene [37]. In this study, grape seed oil extracts were shown to be the most potent in the $\beta$-carotene bleaching assay compared to the other edible oils (Table 2). Among the identified phenolic acids, benzoic acid and vanillic acid were observed as the major phenolic compounds, and esculetin, isoquercetin, myricetin, luteolin, and kaempferol were the principal flavonoids in most edible oils. Benzoic acid is extensively used in preservatives, flavor enhancers, analgesics, antiseptics, and chemotherapeutics. Fisetin was found in sunflower (Table 5), while sinapic acid was detected only in cotton and perilla (Table 4).

The antimicrobial activity of the edible oils was examined on two common bacteria-S. aureus and E. coli. The results demonstrated that all of the oils possessed antimicrobial activity on both S. aureus and E. coli (Table 6). Friedman et al. [38] reported that edible oils were widely accepted because they possessed unimaginable medicinal and pharmaceuticals properties, such as antimicrobial activity that could be employed against human pathogens. Rice bran possessed many bioactive compounds [39]. In this study, rice bran showed the highest activity on S. aureus. Moreover, the antibacterial activity of avocado oil extract was the strongest against $E$. coli. Neeman [40] reported that avocado possessed metabolites with antibacterial activity such as 1,2,4-trihydroxy-n-heptadeca-16-en that was extracted from avocado fruit and seeds. Other studies noted that avocado exerted strong antimicrobial activity, including the defensin PaDef which has a $\gamma$-core motif, which was also important for structure stabilization [41,42]. Furthermore, tannins, catechin flavones, and polyphenolics in seeds and immature fruits of avocado may also play a role in the antimicrobial activity [43].

The consumption of edible oils in Japan is increasing [23]; hence, the findings of this study provide useful information on the antioxidant and antimicrobial properties of the most available essential oils in Japanese markets. However, further analyses should be carried out by widening the sample collection and analyzing oils produced in controlled conditions (i.e., in laboratory) so as to eliminate the influence of different processing conditions, which might affect the results obtained in this study. Useful information on the antioxidant and antimicrobial properties, as well as chemical profiles, may help customers to have more choices in the consumption of the edible oils in Japan's markets.

Author Contributions: Tran Dang Xuan revised and approved the final submission of the manuscript. Gu Gangqiang conceived the idea, and conducted the study. Tran Dang Khanh, Truong Ngoc Minh wrote the manuscript. Tran Ngoc Quy assisted in the manuscript preparation.

Conflicts of Interest: The authors declare no conflict of interest.

\section{References}

1. Kongbonga, Y.G.M.; Ghalila, H.; Onana, M.B.; Majdi, Y.; Lakhdar, Z.B.; Mezlini, H.; Ghalila, S.S. Characterization of vegetable oils by fluorescence spectroscopy. Food Nutr. Sci. 2011, 2, 692-699. [CrossRef]

2. Rotondo, A.; Salvo, A.; Gallo, V.; Rastrelli, L.; Dugo, G. Quick unreferenced NMR quantification of squalene in vegetable oils. Eur. J. Lipid Sci. Technol. 2017, 11, 1700151. [CrossRef]

3. Salvo, A.; Torre, G.L.L.; Rotondo, A.; Mangano, V.; Casale, K.E.; Pellizzeri, V.; Clodoveo, M.L.; Cicero, N.; Dugo, G. Determination of squalene in organic extra virgin olive oils (EVOOs) by UPLC/PDA using a single-step SPE sample preparation. Food Anal. Methods 2017, 10, 1377-1385. [CrossRef]

4. Tranchida, P.Q.; Salivo, S.; Bonaccorsi, I.; Rotondo, A.; Dugo, P.; Mondello, L. Analysis of the unsaponifiable fraction of lipids belonging to various milk-types by using comprehensive two-dimensional gas chromatography with dual mass spectrometry/flame ionization detection and with the support of high resolution time-of-flight mass spectrometry for structural elucidation. J. Chromatogr. A 2013, 1313, $194-201$. [PubMed]

5. Salvo, A.; Rotondo, A.; Torre, G.L.L.; Cicero, N.; Dugo, G. Determination of 1,2/1,3-diglycerides in Sicilian extra-virgin olive oils by1H-NMR over a one-year storage period. Nat. Prod. Res. 2017, 31, 822-828. [CrossRef] [PubMed]

6. Aluyor, E.O.; Ori-Jesu, M. The use of antioxidants in vegetable oils-A review. Afr. J. Biotechnol. 2008, 7, $4836-4842$. 
7. Dugo, G.; Rotondo, A.; Mallamace, D.; Cicero, N.; Salvo, A.; Rotondo, E.; Corsaro, C. Enhanced detection of aldehydes in extra-virgin olive oil by means of selective band NMR spectroscopy. Physica A 2015, 420, 258-264. [CrossRef]

8. Rotondo, A.; Salvo, A.; Giuffrida, D.; Dugo, G.; Rotondo, E. NMR analysis of aldehydes in Sicilian extra-virgin olive oils by DPFGSE techniques. Atti della Accademia Peloritana dei Pericolanti-Classe di Scienze Fisiche Matematiche e Naturali 2011, 89, C1A8901002.

9. Naccari, C.; Rando, R.; Savo, A.; Donanto, D.; Bartolomeo, G.; Mangalo, V.; Turco, V.L.; Dugo, G. Study on the composition and quality of several Sicilian EVOOs (harvesting year 2015). Ital. J. Fat Subst. 2017, 94, 231-237.

10. Mallamace, D.; Vasi, S.; Corsaro, C.; Maria, C.N.; Clodoveo, L.; Dugo, G.; Cicero, N. Calorimetric analysis points out the physical-chemistry of organic olive oils and reveals the geographical origin. Physica A 2017, 486, 925-932. [CrossRef]

11. Corsaro, C.; Mallamace, D.; Vasi, S.; Ferranteli, V.; Dugo, G.; Cicero, N. ${ }^{1}$ H HR-MAS NMR Spectroscopy and the metabolite determination of typical foods in Mediterranean diet. J. Anal. Methods Chem. 2015, 2015, 175696. [CrossRef] [PubMed]

12. Corsaro, C.; Mallamace, D.; Vasi, S.; Naccari, C.; Salvo, A.; Giofre, S.V.; Dugo, G. HR-MAS and NMR towards foodomics. Food Res. Int. 2016, 89, 1085-1094. [CrossRef]

13. Clodoveo, M.L.; Camposeo, S.; Amirante, R.; Dugo, G.; Cicero, N. Research and Innovative Approaches to Obtain Virgin Olive Oils with a Higher Level of Bioactive Constituents; AOCS Press: Urbana, IL, USA, 2015; pp. 179-215.

14. Patil, D. Role of antioxidants in stability of edible oil. Trends Post-Harvest Technol. 2013, 1, 68-73.

15. Caponio, F.; Pasqualone, A.; Gomes, T. Effects of conventional and microwave heating on the degradation of olive oil. Eur. Food Res. Technol. 2002, 215, 114-117.

16. Ferreira, I.F.R.; Baptista, P.; Vilas-Boas, M.; Barros, L. Free-radical scavenging capacity and reducing power of wild edible mushrooms from northeast Portugal: Individual cap and stipe activity. Food Chem. 2007, 100, 1511-1516.

17. Bouras, M.; Chadni, M.; Barba, F.J.; Grimi, N.; Bals, O.; Vorobiev, E. Optimization of microwave-assisted extraction of polyphenols from Quercus bark. Ind. Crops Prod. 2015, 77, 590-601. [CrossRef]

18. Dilini, B.; Terrence, M. Antioxidant activity and total phenolic content of sesame (Sesamum indicum L.) seed oil. Trop. Agric. Res. 2013, 24, 296-302.

19. Gutfinger, T. Polyphenols in olive oils. J. Am. Oil Chem. Soc. 1981, 58, 966-968. [CrossRef]

20. Li, A.; Li, S.; Zhang, Y.J.; Xu, X.R.; Chen, Y.M.; Li, H.B. Resources and biological activities of natural polyphenols. Nutrients 2014, 6, 6020-6047. [PubMed]

21. Hammer, K.A.; Carson, C.F.; Riley, T.V. Antimicrobial activity of essential oils and other plant extracts. J. Appl. Microbiol. 1999, 10, 1365-2672. [CrossRef]

22. Islam, K.; Rowsni, A.A.; Khan, M.; Kabir, S. Antimicrobial activity of ginger (Zingiber officinale) extracts against food-borne pathogenic bacteria. Int. J. Sci. Environ. Technol. 2014, 3, 867-871.

23. Agriculture and Agri-Food Canada: Vegetable oils in Japan. Available online: http:/ /www.agr.gc.ca/resources/ prod/Internet-Internet/MISB-DGSIM/ATS-SEA/PDF/6894-eng.pdf (accessed on 2 February 2018).

24. Elzaawely, A.A.; Xuan, T.D.; Tawata, S. Antioxidant and antibacterial activities of Rumex japonicus HOUTT aerial parts. Biol. Pharm. Bull. 2005, 28, 2225-2230. [CrossRef] [PubMed]

25. Chatha, S.A.S.; Anwar, F.; Manzoor, M.; Bajwa, J.R. Evaluation of the antioxidant activity of rice bran extract using different antioxidant assays. Grasas y Aceites 2006, 57, 328-335.

26. Medini, F.; Fellah, H.; Ksouri, R.; Abdelly, C. Total phenolic, flavonoid and tannin contents and antioxidant and antimicrobial activities of organic extracts of shoots of the plant Limonium delicatulum. J. Taibah Univ. Sci. 2014, 8, 216-224. [CrossRef]

27. Djeridane, A.; Yousfi, M.; Nadjemi, B.; Boutassouna, D.; Stocker, P.; Vidal, N. Antioxidant activity of some algerian medicinal plants extracts containing phenolic compounds. Food Chem. 2006, 97, 654-660. [CrossRef]

28. Xuan, T.D.; Tsuzuki, E.; Terao, H.; Matsuo, M.; Khanh, T.D. Correlation between growth inhibitory exhibition and suspected allelochemicals (phenolic compounds) in the extract of alfalfa (Medicago sativa L.). Plant Prod. Sci. 2003, 6, 165-171. [CrossRef] 
29. Lestari, E.S.; Severin, J.A.; Filius, P.M.; Kuntaman, K.; Duerink, D.O.; Hadi, U.; Wahjono, H.; Verbrugh, H.A. Antimicrobial Resistance in Indonesia: Prevalence and prevention (AMRIN). Antimicrobial resistance among commensal isolates of Escherichia coli and Staphylococcus aureus in the Indonesian population inside and outside hospitals. Eur. J. Clin. Microbiol. Infect. Dis. 2008, 27, 45-51. [CrossRef] [PubMed]

30. Ferreira, C.; Voorst, F.; Martins, A.; Neves, L.; Oliveira, R.; Kielland-Brandt, M.C.; Lucas, C.; Brandt, A. A member of the sugar transporter family, Stl1p is the glycerol/H+ symporter in Saccharomyces cerevisiae. Mol. Biol. Cell. 2005, 16, 2068-2076. [CrossRef] [PubMed]

31. Anwar, F.; Przybylski, R. Effect of solvents extraction on total phenolics and antioxidant activity of extracts from flaxseed (Linun usitatissimum L.). Acta Sci. Pol. Technol. Aliment. 2012, 11, 293-301. [PubMed]

32. Kasote, D.M.; Hegde, M.V.; Deshmukh, K.K. Antioxidant activity of phenolic components from $n$-butanol fraction (PC-BF) of defatted flaxseed meal. Am. J. Food Technol. 2011, 6, 604-612. [CrossRef]

33. Karamac, M.; Kosinska, A.; Esrella, I.; Hernandez, T.; Duenas, M. Antioxidant activity of phenolic compounds identified in sunflower seeds. Eur. Food Res. Technol. 2012, 235, 221-230. [CrossRef]

34. Bail, S.; Stuebiger, G.; Krist, S.; Unterweger, H.; Buchbauer, G. Characterisation of various grape seed oils by volatile compounds, triacylglycerol composition, total phenols and antioxidant capacity. Food Chem. 2007, 108, 1122-1132. [CrossRef] [PubMed]

35. Doshi, P.; Adsule, P.; Banerjee, K.; Oulkar, D. Phenolic compounds, antioxidant activity and insulinotropic effect of extracts prepared from grape (Vitis vinifera L.) byproducts. J. Food Sci. Technol. 2015, 52, 181-190. [CrossRef] [PubMed]

36. Li, H.; Wang, X.Y.; Li, P.H.; Li, Y.; Wang, H. Comparative study of antioxidant activity of grape (Vitis vinifera) seed powder assessed by different methods. J. Food Drug Anal. 2008, 16, 67-73.

37. Barreira, J.C.M.; Ferreira, I.C.F.R.; Oliveira, M.B.P.P.; Pereira, J.A. Antioxidant activities of the extracts from chestnut flower, leaf, skins and fruit. Food Chem. 2008, 107, 106-1113. [CrossRef]

38. Arpan, D.; Praveen, J.; Ajay, S. Antibacterial activity of rice bran oil. Recent Res. Sci. Technol. 2013, 5, 18-19.

39. Friedman, M. Rice brans, rice bran oils, and rice hulls: Composition, food and industrial uses, and bioactivities in humans, animals, and cells. Agric. Food Chem. 2013, 61, 10626-10641. [CrossRef] [PubMed]

40. Neeman, I.; Lifshitz, A.; Kashman, Y. New antibacterial agent isolated from the avocado pear. Appl. Microbiol. 1970, 19, 470-473. [PubMed]

41. Uma, S.S.; Raghoottama, P.; Jagdeep, K.; Thomas, J.S.; Dilip, M.S. Structure-activity determinants in antifungal plant defensins msdef1 and mtdef4 with different modes of action against Fusarium graminearum. PLoS ONE 2011, 6, e18550.

42. Jaquelina, J.G.-R.; Rodolfo, L.-G.; Luis, M.S.-R.; Rafael, S.-G.; Luis, C.; Rodríguez-Zapata, A.O.-Z.; Joel, E.L.-M. Antibacterial activity of defensin padef from avocado fruit (Persea americana var. drymifolia) expressed in endothelial cells against Escherichia coli and Staphylococcus aureus. Biomed. Res. Int. 2013, 2013, 986273.

43. Raymond Chia, T.W.; Dykes, G.A. Antimicrobial activity of crude epicarp and seed extracts from mature avocado fruit (Persea americana) of three cultivars. Pharm. Biol. 2010, 48, 753-756. [CrossRef] [PubMed]

(C) 2018 by the authors. Licensee MDPI, Basel, Switzerland. This article is an open access article distributed under the terms and conditions of the Creative Commons Attribution (CC BY) license (http://creativecommons.org/licenses/by/4.0/). 